\title{
Economic Factors That Influence Mortality Rate. An Evidence From Ghana
}

\author{
Michael Kwabena Ofori* ${ }^{*} \quad$ Yinfei Chen \\ School of Finance and Economics, Jiangsu University, \\ No. 301 Xuefu Road, Zhenjiang, Jiangsu, P. R. China
}

\begin{abstract}
The purpose of this paper is to analyze how economic growth influence mortality rate in Ghana from the year 2000 to 2016 based on a dynamic model augmented with life expectancy, employment and economic growth. Results show that life expectancy is the critical most important factor in changing the level of mortality rate negative. Economic growth (GDP) and employment have plausible negative signs to mortality rates. However, they will significantly have influence in the case of discrete growth policy implementation and thus demonstrating the importance of living standards to mortality. Also, Granger causality tests show a significant relationship from employment and economic growth and reflects their importance in changing the observed levels of mortality.

Keywords: Life Expectancy, Mortality rate, Employment, Unemployment, Medicare, Economic Growth, Granger causality.
\end{abstract}

DOI: $10.7176 / \mathrm{JESD} / 11-4-05$

Publication date: February $29^{\text {th }} 2020$

\subsection{Introduction}

Life expectancy refers to the portion of the normal life span a creature is estimated to survive established at the time of birth, its present age, and demographic conditions. The lifespan of a Ghanaian is relatively short in this $21^{\text {st }}$ century with many Ghanaians suffering untimely deaths. Recent information circulated by the World Health Organization (WHO) states that life expectancy at birth in Africa is 61.2 years and approximately 62.4 years in Ghana. This puts Ghana on $25^{\text {th }}$ in Africa Life Expectancy at birth ranking (WHO, 2019). Ghana's life expectancy was observed over some few years, and it was identified that since 2008 life expectancy has increased at an annual rate of approximately $0.46 \%$.

The country's economy GDP is ranked $73^{\text {rd }}$ in the world as of 2018 by the World Bank, which shows major development to previously ranked $85^{\text {th }}$ in 2013 (Bank, 2019). Ghana had a significant increase in its economy in 2017 after a struggle in the previous years. The financial deficit decreased from $6 \%$ of the gross domestic product (GDP) in 2017 from 9.3\% in 2016, reinforced by severe economic amalgamation efforts (World Bank, 2018).

Under labor force, employment and unemployment are seen as the result of the interest between supply and demand for labor. An employed person (worker) is someone who has been hired directly or through any agency with or without the knowledge of the principal employer, whether for remuneration or not, in any manufacturing process, or in any other kind of work incidental to, or connected with, the manufacturing process or subject of the manufacturing process, but does not include any member of the armed forces of the union (Padhi, 2019).

Many researchers have tried to come up with a clear understanding and interpretation between the complex relationship that exists between employment and mortality and also many other economic conditions. Ghana's unemployment rate amplified from $2.30 \%$ in 2016 to $2.40 \%$ in 2017 . The unemployment rate in Ghana averaged $5.41 \%$ from 1991 until 2017, attaining an all-time high of $10.40 \%$ in 2000 and a record low of $2.20 \%$ in 2013 . Joblessness has become a common denominating factor in today's economy, as the general population complains of not finding jobs. This has become a common phenomenon in Africa and Ghana is not an exception as whitecollar jobs are affected most. The unemployment rate of a country is often determined by the number of individuals who are enthusiastically searching for employment as a proportion of the labor force.

The issue of unemployment has become a national issue that needs close attention and careful strategy to eliminate it drastically. The rate of unemployment has forced the youth into taking on jobs that stress them and criminal activities leading to violence and death. Unemployment causes poverty, and with no social welfare system, poverty increases further. Unemployment has been seen to be linked with a high risk of mortality from suicidal tendencies, psychological stress, and other health-related behaviors as well.

The death rate in Ghana has been on a constant decrease since 2005, which recorded 10.1 per 1,000 people. The death rate of Ghana fell gradually from 10.1 per 1,000 people in 2005 to 8.1 per 1,000 people in 2016. Many programs have been put in place internationally and locally to prevent the menace of high mortality rate, but little achievement has been made in certain causes of the mortality rate since a death has several causes. Maternal mortality and infant mortality have taken attention to the health center for years now.

In this study, the researcher aims to explore the perception that many other factors apart from diseases have an influence on mortality rate in Ghana. The study examines socioeconomic factors that may influence the mortality. The focus is on life expectancy, economic growth, and unemployment on mortality rate in Ghana. 
To this end, this paper investigates how life expectancy impacts mortality rate on a model augment with some of the important macroeconomic variables- employment and economic growth as the moderator variables in determining the level of resource availability for better living standards to offset mortality. This is based on a dynamic model based on time-series data from the year 2000-2016 to appropriately demystify the true underlying relationship between mortality and life expectancy in the backdrop of employment and GDP growth. Results of ARDL demonstrated that life expectancy is the most critical in implicating life expectancy while employment and GDP despite reducing mortality rates, their implication need feasible policies for significant influence. A similar show is demonstrated by Granger causality analysis, which portrays life expectancy, employment rates and GDP growth Granger causes mortality rates.

\subsection{Problem statement}

The mortality rate in Ghana has been influenced by many factors, mainly diseases as described by the Ghana Health Directorate. The Public health determinations through hygienic procedures concentrated on reducing exposure to transmittable infections played a major part in reducing the mortality rate in developed as well as less developed countries, but the determinations mainly aided the urban areas (Cutler \& Miller, 2005). In Ghana, citizens in the rural areas are highly exposed to diseases due to lack of social amenities (equipped health care facilities) which increase the mortality rate. This can also be said for urban areas, which has a problem of overcrowding, there is lots of pressure on the available social amenities and also many high level of competition for people looking for work. The increasing rate of unemployment has forced the youth to engage in hard labor activities, which reduce their strength, but do not earn enough to have a balanced diet. Less availability in diet and nutrition decode into a higher death rate by decreasing body composition.

This research helps predict the relationship between mortality and the under-listed socioeconomic factors under review. It further enlightens us regarding the nature of effect of unemployment on mortality.

\subsection{Literature review}

Mortality related differences persist in both developed and developing countries. The relationship that exists between mortality, life expectancy, economic condition (GDP) and unemployment has been a topic of great concern to many researchers and also the world. Researchers desire to know the relationship between mortality and economic conditions became intense after the global financial crises in 2008.

In 2006, a research was conducted by (Musić Milanović et al., 2006) on the life expectancy and mortality difference among populous on Croatian Island and the Mainland using population data collected in Croatia in 2001 and also data on mortality. They used life table and standardized mortality rate to analyze the data. In their research, they identified that the Croatian Island resident had a greater life expectancy than the mainland Croatian. The researchers also identified that there was a significantly lower mortality rate between the ages of 50-64 and 65-79 years for residents on the island as compared to the general Croatian population.

A recent study identified an increase in mortality as there's a reduced life expectancy due to ambient air pollution based on a time series data from 2000-2016 within North America, Central and East Asia, Europe and Pacific regions (Sarkodie, Strezov, Jiang, \& Evans, 2019).

Furthermore, (Cristia, 2009) came up with the findings that, there's a high rate of mortality among different age and sex groups when identifying whether death and life expectancy variances by socioeconomic groups in the United States of America. Also, the researcher identified that there's an increase in life expectancy differentials by earnings during a period for men and women in different control proportions.

In recent years, many researchers have tried to explain the ratio between employment and mortality. To be unemployed has a higher tendency to lead an individual to death as observed by many scholars. Even though many studies has proved that there's a higher mortality rate for individuals who lose their job, there are other wide ranges of studies that prove otherwise.

This comparison was addressed in research due to the mass unemployment in Europe among the youth. It indicated that there's an increase in mortality due to unemployment (Vågerö \& Garcy, 2016). In their research, they observed that circulatory diseases did not have any influence on unemployment even thou suicidal tendencies and alcohol-related diseases within men and women had a great influence on unemployment. Men had a higher mortality rate from alcohol-related diseases as compared to women who experienced unemployment. The researcher also observed that there is no uniform effect of unemployment across the population.

The job people do greatly affects their mortality. Some jobs are highly risky in terms of being prone to accidents or been exposed to toxic chemicals. Some jobs are also physically engaging leading to poor health. Occupations also reflects the educational level and level of income, therefore it is expected to have a strong relationship with mortality. Researchers have tried to establish the relationship between employment and mortality and a strong link has been established by many. In research (Rogers, Hummer, \& Krueger, 2005), the researchers indicated that in a higher occupation with higher income results in lower death rates.

Most scholars have come up with the assumption and arguments based on the fact that employment and 
unemployment greatly affect the mortality rate in the world. Some scholars argue that an escalation in unemployment decreases the death rate drastically in the short run while other scholars also argue that unemployment increases the mortality rate of a country in the long run. In this research, employment is defined as the contractual agreement between an employer and an employee where the employer engages the employee to work or perform a duty on his/her (employer) behalf for an agreed amount of money payable based on the contractual agreement, whether monthly, weekly daily or on a time basis.

Unemployment, on the other hand, is where there is no enough job to be done by the young and vibrant population who are willing to work for agreed terms and conditions. In this effect, unemployment has been equated by some scholars as joblessness but the case of joblessness cannot be argued about in relating to being unemployed. An individual getting a job to do and be productive is said to increase a person's social standards and also gives him/her a happy life. In another way, unemployment can cause depression, suicidal tendency, and even illness. The problem of unemployment is an issue right at the moment Ghana gained independence.

(Baah-Boateng, 2015) identified in his research on unemployment in Ghana that, there is a high level of unemployment among the youth than the older ones. In his research, he explained that unemployment is due to an individual's inability to find the job of their choice even thou Ghana's economy is growing.

(Pekka T Martikainen, 1996) conducted similar research in Finland based on the excess mortality of unemployed men and women during a period of a rapid increase in unemployment. They based their research on the Finnish population between the ages of 25-59 years of their sociodemographic data. They observed that the unemployment rate of individuals between 1987 and 1992 had a high level of mortality rate as compared to employed individuals. There was a high mortality for jobless individuals who gained re-employment than those who already had their job. In a recent study, excess mortality of $47 \%$ was observed among men unemployed or working part-time for reasons other than illness after adjustment for age, geographic region, social class, cigarette smoking, alcohol consumption, weight and known pre-existing disease. However, causal attribution of mortality due to unemployment remains difficult because most studies have only adjusted for a limited range of potential confounding factors and inaccuracy in the measurement of known cofounders may leave residual confounding effects.

\subsection{Factors affecting mortality}

There are various factors which play important roles in determining the mortality of groups of people. These factors are intermingled and difficult to disassociate from each other yet the government has to identify specific mortality risk factors for measures to be put in place to curtail the effects. Aside from age and sex, on a broader note, standard of living can be used to describe the major factor influencing mortality, and this includes various factors such as occupation, nutrition, housing, climate, education, government policies, and genetics.

Some critics argue that the death rate is peculiar to each individual, as the various elements contributing to the quality of life vary from one person to another. This seems quite plausible, as there is some information which may be private to the individual and computing mortality based on these known facts may be more accurate. In spite of its merits, this approach may waste time when dealing with a large population, where grouping lives in homogeneous groups will be faster in producing generalized results.

In most OECD countries, approximately half of their GDP is used to fund government activities. These activities are usually known as government expenditure and can be associated with mortality and economic conditions. However, one contributing factor (policy) that helps to improve a country with low GDP is macroeconomic growth. This is because, the living standards of citizens in a country with high economic growth will change both in a short and long term. Citizens will now be able to afford quality health care, eat nutritious meals, live comfortably and so on, which will lead to a decline in the mortality rate.

\subsection{Methodology}

The dataset consists of four variables: mortality rate, life expectancy, gross domestic product per capita and employment. The series were extracted from the world data bank. The study examined a section of employed men and women from the year 2000 to 2016. Following employment status in 2000 was observed (in work or unemployed) and the relative all-cause mortality risk of unemployment between 2000 and 2016 was estimated together with life expectancy and economic growth. To account for potential selection into unemployment of those in poor health, a propensity score matching approach was used.

\subsection{Model analysis}

One of the objectives is to determine the relationship between economic growth, life expectancy, and the standard of living with the mortality rate in both the short and long run time domains. In our study, the standard of living is represented by employment while GDP as output represents economic growth. In the study, the variable abbreviation takes the format: MRT for mortality rate, LE for life expectancy, GDP for output, and EMP for employment. The simple basic representation used to expedite the relationship and impact of GDP, employment 
and life expectancy on the mortality rate takes the format of Equation 1 below.

$$
M R T_{t}=k+\lambda_{1} L E_{t}+\lambda_{2} \ln G D P_{t}+\lambda_{3} E M P_{t}+e_{t}
$$

In the equation, $k \lambda_{1} \lambda_{2} \lambda_{3}$ and are the parameters to be estimated. ${ }_{t}$ Represents a iid mean $\mu_{\text {and }}$ standard deviation $\delta$. In the real case, ${ }^{e_{t}}$ marshalises all other factors that affect the mortality rate like climatic hazards, medication, social misfortunes, etc. Our expectation is that, $\lambda_{1}, \lambda_{2}$ and $\lambda_{3}$ to be negatively signed to work to reduce the mortality rate.

Due to the nature of and behavior of the variables, they were mixture stationery. Thus, we estimated equation 1 using the autoregressive distributed lag (ARDL) econometric technique by (Pesaran, Shin, \& Smith, 2001). The model estimates both long run and the short-run relationship between the variable and the adjustment coefficients, in the end, provide the variable integrated of order 1 or less. Equation 2 represents the model.

$\Delta M R T_{t}=k+\lambda_{0} \sum_{i=1}^{l} \Delta M R T_{t-1}+\lambda_{1} \sum_{i=0}^{l} \Delta E_{t-1}+\lambda_{2} \sum_{i=0}^{l} \Delta \ln G D_{t-1}+\lambda_{3} \sum_{i=0}^{l} \Delta \ln E M_{t-1}+\beta M R T_{t-1}+\beta L E_{t-1}+\beta_{2} \ln G D_{t}+\beta_{2} E M_{t-1}+e_{t}$

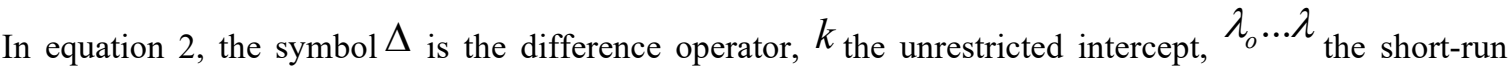
coefficients, $\beta_{0} \ldots \beta_{2}$ the long-run coefficients, and $e_{t}$ the white noise innovation. In shorthand, the ARDL equation 2 can be represented:

$\Delta M R T_{t}=k+\lambda_{y} \sum_{i=1}^{l} \Delta M R T_{t-1}+\sum_{i=0}^{l} \lambda_{i} \Delta x_{t-1}+\sum_{i=0}^{l} \beta_{x} M R T_{t-1}+\sum_{i=0}^{l} \beta_{i} x_{t-1}+e_{t}$

Where $\Delta M R T_{t}$ is the dependent variable, ${ }^{\lambda_{y}}$ and $\beta_{x}$ denotes the coefficient of lagged short-run and longrun variables, variable from Equation $2, \lambda_{i} \beta_{i}$ and while $l_{\text {is the optimal lag-by-lag selection criterion? }}$

The coefficient of adjustments is generated by default when the long-run coefficients are orthogonalized within the system. The precondition for ARDL method modeling requires that the variables should be stationary in order 1 as the highest.

First, we started with unit root testing and tabled these results in table 1. This is crucial in macroeconomic modeling and specifically for our case to determine the order of integration of the variables, which aided in model selection. The autoregressive distributed lag structure (ARDL) model used herein best suits the data structure. The dataset is mixture stationery without any second-order stationarity. The equation then estimated by an (ARDL).

Table 1. Unit root test

\begin{tabular}{llll}
\hline \multicolumn{4}{l}{ Augmented Dickey-Fuller } \\
\hline & Level & $\Delta$ & Integration order \\
\cline { 2 - 4 } MRT & {$[-8.688]^{* * *}$} & - & $\mathrm{I}(0)$ \\
LE & {$[-0.909]$} & {$[-4.867]^{* * *}$} & $\mathrm{I}(1)$ \\
GDP & {$[-3.286]^{*}$} & - & $\mathrm{I}(0)$ \\
EMP & {$[-2.414]$} & {$[-3.467]^{* *}$} & $\mathrm{I}(1)$ \\
\hline
\end{tabular}

$* * *, * * *$ Significance at 1,5 and $10 \%$, Numbers in square brackets denotes the t statistics,

$H_{0}$

$H_{0} \sim$ Null hypothesis -unit root present. Test equation has done at the trend and constant. Lags used was 1 for MRT and GDP and zero otherwise.

The Initial step in ARDL modeling entailed determining the maximum lags for the variables, which by Akaike Information Criterion ranged from 1 to 4 for all variables. However, in the basic ARDL framework regression, we adopted 1 lag to avoid collinearity problems. Secondly, we adopted the determination of the matrix lags to build the bound test cointegration test equation. The bound test results presented in table 2 were thus regressed from Equation 2 on the lag structure $\left(\begin{array}{llll}1 & 1 & 1 & 0\end{array}\right)$.

Table 2. ARDL bound test

\begin{tabular}{llll} 
Table 2. ARDL bound test & \multicolumn{3}{l}{$1 \%$ critical value } \\
\hline & Value & $\mathrm{I}(0)$ & $\mathrm{I}(1)$ \\
\cline { 2 - 4 } F-statistics & 10.785 & 7.759 & $10.419^{* * *}$ \\
t-statistics & -2.271 & $-4.106^{* * *}$ & -5.346 \\
\hline
\end{tabular}

The null hypothesis-No level relationship, ${ }^{* * *}$ significance at $5 \%$

Upon confirming the presence of cointegration relationship, we regressed the ARDL to estimate both longrun and short-run coefficients and the cointegration speed. The cointegration speed refers to the magnitude at 
which the system relationship between mortality rate and the determining factor re-adjust back to the equilibrium state after distortion. The results depicting the long run, short-run and adjustment speed are tabled in 3.

Table 3 ARDL results

\begin{tabular}{lll}
\hline & Coefficient & T-statistics \\
\hline Adjustment & -0.064 & $-2.27^{* *}$ \\
\hline Long run & & \\
\hline LnGDP & -2.665 & -0.90 \\
LE & -10.484 & $-3.61^{* *}$ \\
EMP & -0.699 & -0.68 \\
\hline Short-run & & \\
\hline D.lnGDP & 0.201 & 1.76 \\
D.LE & 5.652 & $7.26^{* *}$ \\
Constant & 44.859 & $3.20^{* *}$ \\
\hline
\end{tabular}

** significance at $5 \%$

Part of our aim as stated initially was to analyses the direction and magnitude of causality among the variables. Thus, in Table 4, we presented the results of Granger causality depicting the path of causality and significance.

Table 4. Granger Causality

\begin{tabular}{lllll}
\hline & MRT & LE & EMP & GDP \\
\hline MRT & -- & $1583.9^{* * *}$ & 2.979 & 0.279 \\
GDP & $9.537^{* * *}$ & $70.252^{* * *}$ & 0.292 & \\
LE & $310.82^{* * *}$ & -- & 0.419 & 0.370 \\
EMP & 1.035 & $10.54 * * *$ & & 1.322 \\
\hline
\end{tabular}

$* * *$ Significance at $1 \%$, Causality direction is from left to right variable

In the preceding step, we analyzed and presented diagnostic checkups for the model. A good estimated model should have a homoscedastic variance of residuals, free from serial correlation and very stable with normally distributed residuals. Consequently, we regressed the Durbin Watson, Breusch, Godfrey and White tests for serial correlation and heteroscedasticity test while Jarque Bera and Cusum test were used to test the normality and stability of our model. These results are in table 5 and figure 1 below respectively.

Table 5. Diagnostic checkups

\begin{tabular}{lll}
\hline & Statistic & Null hypothesis \\
\hline Breusch Pagan & 0.386 & No Serial correlation \\
Durbin Watson & 1.893 & \\
White test & 16.00 & Residuals are homoscedastic \\
\hline
\end{tabular}

$* * *, * *,{ }^{*}$ significance at 1,5 and $10 \%$

CUSUM squared

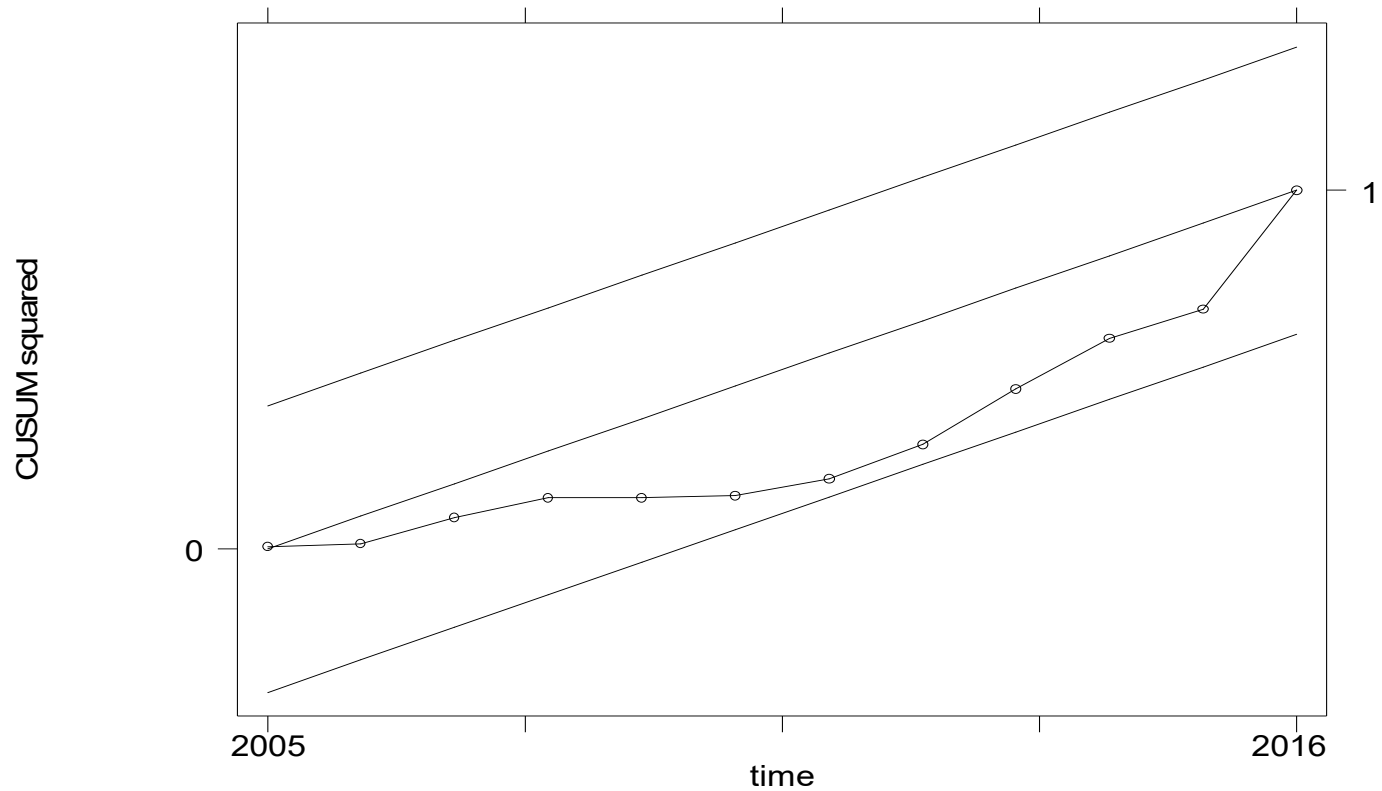

Figure 1. Cusum test of model Stability. 


\subsection{Analysis and Discussion}

Concerning table 1, we presented the stationary test. MRT and GDP rejected the null hypothesis of the unit root presence at a level while LE and EMP rejected it after taking the first difference. Thus, the mortality rate and GDP are stationary at a level while life expectancy and employment series are stationary at first level. This resulted in a mixture stationary series that prompted the use of ARDL regression.

In table 2, the ARDL bound test results were depicted. The result shows that both the F-statistics and Tstatistics does reject the null hypothesis that the series are not cointegrated. Both statistics are significant at I (1) bounds a connotation that they are co-integrated and converge to equilibrium.

According to table 3, we presented the results of ARDL. The results contain both long run, short run, and the adjustment coefficients. To start with the short run, the output is the only one insignificant in affecting the mortality rate. However, the coefficients of life expectancy and constants are statistically significant at $5 \%$. Thus, in the short term, mortality rate, increase by $1 \%$ when life expectancy increases by $5.67 \%$, while the underlying rate of mortality is significant at $44.89 \%$. In the long run, unlike with employment and output, the coefficient of life expectancy is significant at $5 \%$ an intuition that when mortality rate is reduced by $10.48 \%$ when life expectancy is increased by $1 \%$. The adjustment coefficient is as well significant at $5 \%$. In the case of other inefficiencies of mortality causing its instability, the rate converges back to equilibrium at $6.4 \%$ maintaining the natural rate of child deaths. Otherwise, life expectancy is the most crucial element in determining child deaths in both the short run and a long run at $5.65 \%$ and $-10.48 \%$ respectively.

In table 4 , are presented the results of the Granger causality test. We notice both unidirectional and bidirectional causality pathways and are significant at 5\%. A bidirectional causal pathway exists between MRT and LE, while it singles directional causality from GDP to MRT, GDP to LE and EMP to LE. In the short run, the mortality rate and life expectancy are thus the most crucial determines as the granger cause each other. Otherwise, outputs able to ranger cause life expectancy but not directly the mortality rate.

The following tables above presented the diagnostic checkups. In table 5, are the robustness checkups of the model. The table depicts the serial correlation for testing whether the residuals are interrelated, have constant variance and in figure 1 that diagnosed the whole model as to whether it lies between the $95 \%$ confidence band. Thus, both the Breusch Pagan and Durbin Watson statistics at 0.386 and 1.893 were statistically insignificant at the stated significance measures denoting to the fact that the model was free from serial correlation. I addition the White test statistics in 16.00 were also insignificant an intuition that the model's variance is constant are desirable. With raged to figure 1 , the model lies between the $95 \%$ confidence band and hence stable. From the afore-discussed, the ARDL model $(1,1,10)$ used is suitable and sufficient to model the determinants of mortality rate.

\subsection{Conclusion}

This paper implored the influence of life expectancy on the mortality rate on an ARDL model augmented with employment and economic growth (GDP) for 2000-2006. Results demonstrated that life expectancy significantly impacts by reducing the mortality rate. A similar influence is by employment and economic growth, which reduces the rate of mortality, but, the influence will be more significant if feasible policies are intensely implemented.

Based on these results, we recommend that policies to implement should focus on increasing employment opportunities and as well as sustainable wage earnings to the citizens. That is to say, economic growth policies should advance the expansion and creation of more job opportunities to employ a large population of the people. The growth should also invest in the development of the medical sector in pursuit of improved standards of health and Medicare.

\section{References}

Baah-Boateng, W. (2015). Unemployment in Ghana: A Cross Sectional Analysis from Demand and Supply Perspectives. African Journal of Economic and Management Studies (AJEMS), 6.

Bank, W. (2019). Data Catalog. Retrieved 7, 2019, from https://datacatalog.worldbank.org/dataset/gdp-ranking Cristia, J. P. (2009). Rising mortality and life expectancy differentials by lifetime earnings in the United States. Journal of Health Economics, 28(5), 984-995. doi: https://doi.org/10.1016/j.jhealeco.2009.06.003

Cutler, D., \& Miller, G. (2005). The role of public health improvements in health advances: The twentieth-century United States. Demography, 42(1), 1-22.

Musić Milanović, S., Ivicević Uhernik, A., Mihel, S., Pristas, I., Stanić, A., \& Stevanović, R. (2006). Life expectancy and mortality differences between populations on Croatian islands and the mainland. Croatian medical journal, 47(4), 611-618.

Padhi, P. K. (2019). Labor and Industrial Laws, Fourth Edition: PHI Learning Pvt. Ltd.

Pekka T Martikainen, T. V. (1996). Excess mortality of unemployed men and women during a period of rapidly increasing unemployment. The Lancet, 909-912.

Pesaran, M. H., Shin, Y., \& Smith, R. J. (2001). Bounds testing approaches to the analysis of level relationships. Journal of Applied Econometrics, 16, 289-326. doi: 10.1002/jae.616 
Rogers, R., Hummer, R., \& Krueger, P. (2005). Adult Mortality (pp. 283-309).

Sarkodie, S. A., Strezov, V., Jiang, Y., \& Evans, T. (2019). Proximate determinants of particulate matter (PM2.5) emission, mortality and life expectancy in Europe, Central Asia, Australia, Canada and the US. Science of The Total Environment, 683, 489-497. doi: https://doi.org/10.1016/j.scitotenv.2019.05.278

Vågerö, D., \& Garcy, A. M. (2016). Does unemployment cause long-term mortality? Selection and causation after the 1992-96 deep Swedish recession. European journal of public health, 26 (5), 778-783. doi: 10.1093/eurpub/ckw053.

WHO. (2019). Global Health Observatory (GHO) data.

Life $\quad$ expectancy. $\quad$ Retrieved $1 / 09 / 2019, \quad 2019, \quad$ from https://www.who.int/gho/mortality burden_disease/life tables/situation trends text/en/ 